\title{
Computer Technology in the Development of Emotional Intelligence of Children with Intellectual Disabilities
}

\author{
Lidiya F. Fatikhova ${ }^{1} \&$ Elena F. Saifutdiyarova ${ }^{2}$ \\ ${ }^{1}$ M. Akmullah Bashkir State Pedagogical University, Ufa, Russia \\ ${ }^{2}$ Birsk Branch of Bashkir State University, Birsk, Russia \\ Correspondence: Elena F. Saifutdiyarova, High Street, Ponomarevka, Birsk, 452469, Russia.
}

\author{
Received: October 24, 2014 Accepted: December 3, 2014 Online Published: December 18, 2014 \\ doi:10.5539/res.v7n1p130 URL: http://dx.doi.org/10.5539/res.v7n1p130
}

\begin{abstract}
The importance of the problem under analysis is in consequence of increasing role of emotional intelligence in the process of socialization. Therefore, its development becomes particularly important in the adaptation process of children with disabilities. Computer technologies are actively used in child training and skills formation in the modern society. This article aims at the theoretical and practical analysis of the existing computer technologies used in the training of children with disabilities, as well as at the empirical confirmation of their effectiveness in training children with intellectual disabilities. The paper summarizes the results of a study verifying the effectiveness of the inclusion of computer technology in the development process of psycho-emotional intelligence of children of 8 to 9 years of age with intellectual disabilities (mixed specific disorders and mild mental retardation). The study was conducted with the help of copyright experimental techniques aimed at identifying children's ability to recognize emotional states in different situations. A statistical analysis of the experimental data with the calculation of Wilcoxon Signed Ranks Test, enabled to reveal changes in the development of emotional intelligence of children with intellectual disabilities while using computer technology in the correcting developing process. A conclusion is made about the effectiveness of the use of computer technology in the psychocorrectional work on the development of emotional intelligence of children with intellectual disabilities.
\end{abstract}

Keywords: computer technology, emotional intelligence, children with intellectual disabilities, children with mixed specific disorders, children with mental retardation

\section{Introduction}

Since the 90-ies of the XX century, interest in the problem of emotional intelligence has been related to its role in the successful adaptation of the person in the educational, professional, management activities, to the ability to effectively express, understand and control one's emotions and be aware of emotions of others (Bar-On, 2007; Goleman, 2009; Bond \& Manser, 2009; Cherniss, 2006). The concept of emotional intelligence, despite its development within the psychological research since the late XX century, remains controversial due to different interpretations of the concept as well as its structure (Mayer, 2000; Nguyen, 2008; Petrides, 2000).

Thus, Mayer, Salovey and Caruso (2000) single out four components of abilities in the structure of emotional intelligence: identification of emotions (own ones' and others'), facilitation of thinking, understanding of emotions (the ability to classify emotions, to interpret the meaning of emotions concerning relationships), control of one's emotions and other people's feelings.

Khlevnaya, Shtroo, and Kiseleva (2012) highlight as components of emotional intelligence the ability to recognize and express emotions, the ability to generate emotions in order to solve specific problems that lead to the ability of an adequate understanding of the events preceding and following the emotions, the ability to regulate one's own and others' emotions.

Studies of the structure of emotional intelligence of children are scarce. Among them is the work of Nguyen (2008), who proposes to distinguish three components in the structure of emotional intelligence of children of 5 to 7 years of age: direction of the child's attention to the human world and the world of emotions, emotional orientation of the child to another child, the child's readiness to take into account the emotional state of another person in their activities. 
Taking into account the importance of emotional intelligence in many spheres of human activity, a question is raised about the need to develop it through psychological means simultaneously with the study of its structure. Thus, since the late 80-s of the XX century in the US education system a purposeful development and testing of a variety of programs has been conducted aimed at building emotional intelligence of primary and secondary school children (Bond \& Manser, 2009). Bond and Manser note that most of these programs aim at building individual emotional and social competencies or components of emotional intelligence such as the ability to regulate emotional behavior, awareness of one's own and others' emotions, empathy, the ability to cope with stress and negative emotions.

It has been started recently to elaborate psychocorrectional programs of forming emotional intelligence in children with disabilities. Thus, on the basis of the analysis of articles on the problems of children with intellectual disabilities, American researchers McClure, Halpern, Wolper, and Donahue (2009) raise the question of teaching skills of recognition and differentiation of other people's emotions to children with mild to moderate mental retardation.

An application of computer technology to solve the problem of emotional intelligence is discussed mainly with respect to such a category of children with developmental disabilities as children with autism. From the point of view of researchers, application of computer programs when working with autistic children, is due to the fact that this category of children prefer a computerized environment, moreover, in the use of computer games children have an opportunity to work at their own pace, and the repetition of the game allows to fix the skills formed (Alcorn, 2011; Jose, 2011). The authors of the computer program FaceSay note that application of the game when working with autistic children led to significant improvements in their ability to read facial expressions of computer characters and define the emotional states of other people (Jose, 2011).

We assumed that children with intellectual disabilities can also use this kind of computer programs: these means included in the process of psychocorrectional work can improve their level of emotional intelligence. Deviations in the mental development of children with intellectual disabilities are not limited only to delays in the development of cognitive processes, but manifest themselves in the emotional sphere, in the lack of emotional and social competence as well. In our view, the need to set the target for the development of emotional intelligence in children with intellectual disabilities is obvious, since, according to Bayanova $(2009,2011,2013)$, any psychic phenomenon, property, or state should be viewed through the interaction of a personality and culture. Thus, skills, provided by emotional intelligence, should also be seen as an opportunity for children with intellectual disabilities to join culture, in this case, the culture of communication and relationships with others.

\section{Materials and Methods}

\subsection{Description of Study Participants}

The study involved children of 8 to 9 years of age, enrolled in special (correctional) educational institutions of types VII (for children with mixed specific disorders) and VIII (for children with mental retardation) in the amount of 40 persons:

1) 20 students with mixed specific disorders with the conclusion of "F 83 Mixed specific developmental disorders" (according to the list of diseases reported in the International statistical classification of diseases and related health problems 10th Revision (2014), 10 of the children make up an experimental group and 10 children a control group;

2) 20 students with mental retardation with the conclusion PMPC "F 70 mild mental retardation" (according to the same list), 10 of them are children of an experimental group and 10-a control group.

\subsection{Stages of the Study}

For the purpose of checking the validity of the hypothesis set, we have developed a set of computer games "I see. I feel. I argue" for the development of emotional intelligence of children with intellectual disabilities and piloted a study in special (correctional) secondary schools, which educate children of the specified group.

The study was conducted in three phases. In the first phase (October-December 2012) the initial level and specific features of social intelligence of children with developmental disabilities were studied. In the second phase (January-March 2013) we created and tested a psychocorrectional program consisting of 15 correctional and developing classes with the use of computer games. In phase III (April-May 2013) the control study evaluated the effectiveness of psychocorrectional activities with the use of computer games.

\subsection{Research Methods}

To identify the level and characteristics of emotional intelligence of children with developmental disabilities and 
check the validity of the hypothesis of the study a diagnostic system, consisting of three methods was used (Fatikhova, 2011):

1) the method of "Study of the ability to recognize emotional states" (Fatikhova \& Kharisova). The technique consists of two sets: the first set is aimed at determining the ability of the child to recognize the emotional states by facial expressions (portrait pictures), the second set is based on the analysis of everyday situations (scene pictures);

2) the method of "Fairy Tale" (Fatikhova) consisting in detecting the child's ability to identify emotional states of fairy tale characters ( animals) based on identification with them;

3) the method of "Study of the ability of the child to determine the emotional state of the people in school situations" (Fatikhova), aimed at exploring the ability to recognize the emotional states of the participants of school situations, to understand the contradiction in the emotional states of participants and situations in which the children find themselves, to interpret these states based on the idea of the situation.

The elaborated set of computer games is aimed at children with intellectual disabilities and includes seven sections: "Feelings", "Behavior", "My Family", "School”, "Conflict”, “Tales", "Caution: Danger!". Each section in turn has 2-3 subsection. Thus, the section "Feelings " includes subsections "My feelings" and "Other people's feelings", section "Behavior" includes tasks "Cross out harsh words", "Find polite words", "Learn to do right", section "My Family"-_"My parents ", "My grandparents", "My brother and sister", section "School"- "School Supplies", "School and the right emotions ", "School Rules", section "Conflicts"-_Causes of Conflict", "How to put up and not to interfere", section "Fairy Tale"- "What do fairy tale characters feel?", "What can we learn from the tale?", section "Caution: Danger"- "Do you know dangerous situations?", "How to avoid danger", "How to behave in a dangerous situation".

Thus, in the correction and development work, we tried to solve the tasks of the formation of the following skills in students with intellectual disabilities: identification of their emotional states and the states of others, the interpretation of emotional states and behavior of partners in communication, interaction with various subjects of communication (parents, other relatives, the teacher, classmates), the regulation and control of their behavior, etc.

\section{Results and Discussion}

The elaborated set of computer games was tested on two groups of children with intellectual disabilities - children with mixed specific disorders and children with mental retardation. Computer games were included in the psychocorrectional process when working with the experimental group, in the control group correction and development activities were carried out without computer games. We used computer games in the preliminary stage of the correction and development activities.

To identify the efficiency of psychocorrectional development of the emotional intelligence of children with intellectual disabilities, statistical analysis of the data by calculating the shift was used (Wilcoxon Signed Ranks Test). Calculation of shifts was carried out in each sample separately for the experimental (hereinafter - EG) and control (hereinafter - CG) groups. The results of statistics are presented in Tables 1 and 2. Statistical analysis of the results of the research was carried out in the statistical package SPSS v 10.0 for Windows corporation StatSoft.

Let us consider the impact of psychocorrectional work aimed at the development of emotional intelligence in the experimental and control groups of children with mixed specific disorders (Table 1). 
Table 1. Comparative efficacy of psychocorrectional development of the emotional intelligence of children with mixed specific disorders (Wilcoxon Signed Ranks Test)

\begin{tabular}{|c|c|c|c|c|c|}
\hline \multirow[t]{2}{*}{ \# } & \multirow[t]{2}{*}{ Options } & \multicolumn{2}{|l|}{ (EG) } & \multicolumn{2}{|l|}{ (CG) } \\
\hline & & 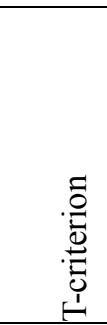 & 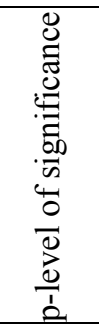 & 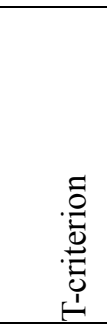 & 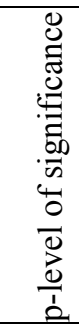 \\
\hline 1 & Recognition of emotional states by facial expressions & 1.667 & 0.095 & 1.342 & 0.18 \\
\hline 2 & $\begin{array}{l}\text { Recognition of emotional states based on the analysis } \\
\text { of everyday situations }\end{array}$ & 2.403 & 0.02 & 1.913 & 0.05 \\
\hline 3 & Recognition of emotional states of fairy tale characters & 1.633 & 0.102 & 1.890 & 0.06 \\
\hline 4 & $\begin{array}{l}\text { Recognition of emotional states of people in school } \\
\text { situations }\end{array}$ & 2.501 & 0.01 & 2.501 & 0.01 \\
\hline
\end{tabular}

Note. Here and in the following table significant shifts are emphasized in bold.

The results of Table 1 show shifts upward for the children with mixed specific disorders of both groups (EG and $\mathrm{CG})$, namely shifts on such parameters as Recognition of emotional states based on the analysis of everyday situations" $(\mathrm{T}=2.403 ; \mathrm{p}<0.02$ in the $\mathrm{EG}$ and $\mathrm{T}=1.913 ; \mathrm{p}<0.05 \mathrm{~kg})$ and "Recognition of emotional states of people in school situations" $(\mathrm{T}=2.501 ; \mathrm{p}<0.01$ in the EG and $\mathrm{T}=2.501 ; \mathrm{p}<0.01 \mathrm{~V} \mathrm{CG})$. However, it should be taken into account that the criterion value and significance level of the shifts in the EG are higher than in the CG. No significant changes have occurred in the ability of children with mixed specific disorders to recognize emotional states by facial expressions and to determine the emotional state of fairy tale characters.

Qualitative analysis of the ascertaining and monitoring stages of the study showed that children with mixed specific disorders reveal a more successful recognition of emotional states based on the analysis of everyday situations than recognition of emotional states by facial expressions, they have typical errors in recognizing emotional states of wonder and tranquility, inaccuracy of their verbal designation.

Now let us refer to the results of the statistical data presented in the Table 2, and reflecting the shift values in terms of emotional intelligence of children with mental retardation.

Table 2. Comparative efficacy of psychocorrectional development of emotional intelligence of children with intellectual disabilities (Wilcoxon Signed Ranks Test)

\begin{tabular}{|c|c|c|c|c|c|}
\hline \multirow[t]{2}{*}{ \# } & \multirow[t]{2}{*}{ Options } & \multicolumn{2}{|l|}{ (EG) } & \multicolumn{2}{|l|}{ (CG) } \\
\hline & & 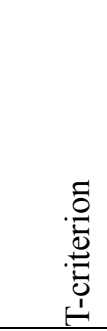 & 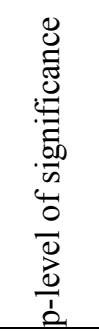 & 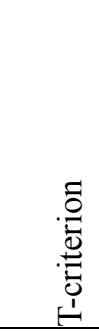 & 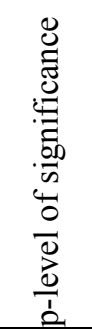 \\
\hline 1 & Recognition of emotional states by facial expressions & 1.430 & 0.153 & 1.136 & 0.256 \\
\hline 2 & $\begin{array}{l}\text { Recognition of emotional states based on the analysis } \\
\text { of everyday situations }\end{array}$ & 2.812 & 0.005 & 1.951 & 0.05 \\
\hline 3 & Recognition of emotional states of fairy tale characters & 0.378 & 0.705 & 1.633 & 0.102 \\
\hline 4 & $\begin{array}{l}\text { Recognition of emotional states of people in school } \\
\text { situations }\end{array}$ & 2.055 & 0.04 & 1.128 & 0.259 \\
\hline
\end{tabular}


Table 2 statistical results show that children with mental retardation of the experimental group reveal significant changes on two indicators - "Recognition of emotional states of the characters based on the analysis of everyday situations" $(\mathrm{T}=2.812 ; \mathrm{p}<0.005)$ and "Recognition of emotional states of people in school situations" ( $\mathrm{T}=$ 2.055; $p<0,04$ ), and of the CG on one indicator - "Recognition of the emotional state of the characters based on the analysis of everyday situations" $(T=1.951 ; p<0.05)$. The children of the EG had a greater index of emotional intelligence than the CG children, as indicated by a higher level of the shift index in the EG. No significant changes occurred in the ability of children with mental retardation to recognize emotional states by facial expressions and to determine emotional states of the fairy tale characters. This result is similar to the result obtained by the group of children with mixed specific disorders.

The experimental data allow us to state that children with mental retardation are at a loss in determining the emotional state of people in portrait pictures, but can identify some of the emotional states of people as participants of specific life situations (in scene pictures). Children with mental retardation cannot determine fairy tale characters' emotions, they retell tale fragments in pictures, but cannot denote their emotions.

\section{Conclusions}

Statistical data suggest that the undertaken psychocorrectional work enabled to increase the ability of children of 8 to 9 years of age with mixed specific disorders and mental retardation to recognize the emotional states of others, both in everyday life and in school situations. When the set of computer games elaborated by the authors of the present paper was added to the psychocorrectional process, the children of these groups were able to more efficiently use the formed skills to recognize emotional states.

Thus, our hypothesis was confirmed, i.e. the inclusion of computer games in the psychocorrectional process of the development of emotional intelligence can increase the level of emotional intelligence of children with developmental disabilities such as mixed specific disorders and mental retardation .

\section{Acknowledgment}

This article was prepared under a grant of the Russian Humanitarian Foundation (project "Computer games as a means of developing social intelligence of children with developmental disabilities" \# 12-06-00041).

\section{References}

Alcorn, A., Pain, H., Rajendran, G., Smith, T., Lemon, O., Porayska-Pomsta, K., ... Bernardini, S. (2011). Social Communication between Virtual Characters and Children with Autism. AIED, LNAI, 6738, 7-14.

Bar-On, R. (2007). The Bar-On model of emotional intelligence: A valid, robust and applicable EI model. Organisations \& People, 14, 27-34.

Bayanova, L. F. (2009). The dialectical psychology of M. M. Rubinstein. Psikhologicheskii Zhurnal, 30(6), 103-109.

Bayanova, L. F. (2011). Hamlet as a reflection of psychological characteristics of the epoch according to L.S. Vygotsky. Voprosy Psikhologii, 6, 77-83.

Bayanova, L. F. (2013). Vygotsky's Hamlet: The dialectic method and personality psychology. Psychology in Russia: State of the Art, 1, 35-42.

Bond, B., \& Manser, R. (2009). Emotional Intelligence Interventions to Increase Student Success (p. 44). Toronto: Higher Education Quality Council of Ontario.

Cherniss, C., Extein, M., Goleman, D., \& Weissberg, R. P. (2006). Emotional Intelligence: What Does the

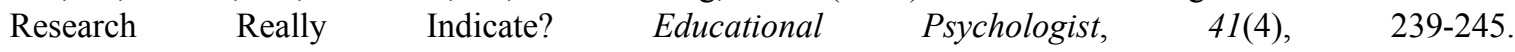
http://dx.doi.org/10.1207/s15326985ep4104_4

Fatikhova, L. F. (2011). Diagnostic system for psycho-pedagogical study of children with intellectual disabilities. In LF Fatikhova (p. 80). Ufa: Ufa branch of IC HPE "MGGU them. M.A. Sholokhov".

Goleman, D. (2009). Emotional Intelligence. In A. P. Isaeva (Ed.), Daniel Goleman: Translation from English (p. 478). AST MOSCOW, Vladimir: VVKT.

International statistical classification of diseases and related health problems. http://apps.who.int/classifications/icd10/browse/Content/statichtml/ICD10Volume2_en_2008.pdf

(2014).

Khlevnaya, E. A., Shtroo, V. A., \& Kiseleva, T. S. (2012). Experimental study on the possibility of emotional intelligence. Psychological Science and Education, 3. Retrieved December 26, 2013, from http://www.psyedy.ru. pdf 
Mayer, J. D., Salovey, P., \& Caruso, D. (2000). Models of Emotional Intelligence. In R. J. Sternberg (Ed.), Handbook of Human Intelligence (2nd ed., pp. 396-420). New York: Cambridge.

McClure, K. S., Halpern, J., Wolper, P. A., \& Donahue, J. J. (2009). Emotion Regulation and Intellectual Disability. Journal on Developmental Disabilities, 2(15), 38-44.

Petrides, K. V., \& Furnham, A. (2000). On the dimensional structure of emotional intelligence. Personality and Individual Differences, 29, 313-320. http://dx.doi.org/10.1016/S0191-8869(99)00195-6

\section{Copyrights}

Copyright for this article is retained by the author(s), with first publication rights granted to the journal. This is an open-access article distributed under the terms and conditions of the Creative Commons Attribution license (http://creativecommons.org/licenses/by/3.0/). 